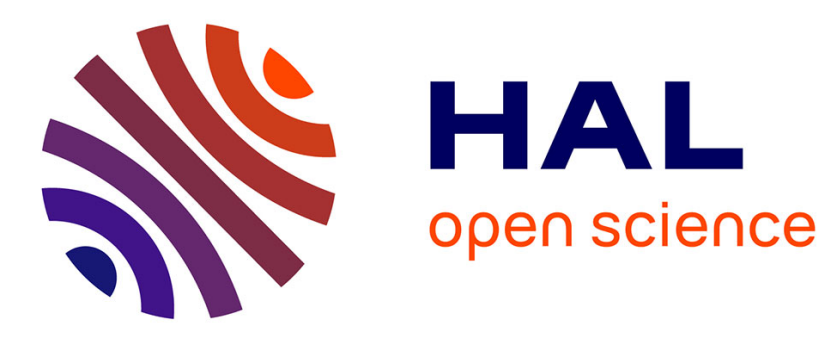

\title{
A spin labelling study of swollen lyotropic lamellar phases
}

\author{
Jean-Marc Di Meglio, Patricia Bassereau
}

\section{To cite this version:}

Jean-Marc Di Meglio, Patricia Bassereau. A spin labelling study of swollen lyotropic lamellar phases. Journal de Physique II, 1991, 1 (2), pp.247-255. 10.1051/jp2:1991158 . jpa-00247510

\section{HAL Id: jpa-00247510 https://hal.science/jpa-00247510}

Submitted on 1 Jan 1991

HAL is a multi-disciplinary open access archive for the deposit and dissemination of scientific research documents, whether they are published or not. The documents may come from teaching and research institutions in France or abroad, or from public or private research centers.
L'archive ouverte pluridisciplinaire HAL, est destinée au dépôt et à la diffusion de documents scientifiques de niveau recherche, publiés ou non, émanant des établissements d'enseignement et de recherche français ou étrangers, des laboratoires publics ou privés. 
Classification

Physics Abstracts

$6810-6116 \mathrm{~N}-6130 \mathrm{E}$

\title{
A spin labelling study of swollen lyotropic lamellar phases
}

\author{
Jean-Marc di Meglio ( ${ }^{1}$ ) and Patricia Bassereau ( ${ }^{2}$ ) \\ (1) Laboratorre de Physıque de la Matıère Condensée (*), Collège de France, 75231 Parıs Cedex \\ 05, France \\ ( $\left.{ }^{2}\right)$ Groupe de Dynamıque des Phases Condensées (**), Unıversité des Sciences et Technıques \\ du Languedoc, 34095 Montpeller Cedex 05, France
}

(Recelved June 29, 1989, revised October 12, 1990, accepted October 22, 1990)

Résumé. - Nous présentons une étude par marquage de spın de phases lamellaires lyotropes dont la distance rétıculaire peut atteındre $8000 \AA$ Nous estımons aınsı la rigıdıté du film interfacial (de l'ordre de $k_{\mathrm{B}} T$ ) et nous montrons que les lamelles des phases les plus gonflées à l'hulle sont certainement parsemées de trous

\begin{abstract}
We report a study by Electron Spın Resonance (ESR) of spın labelled surfactant molecules incorporated in the interfacial film of lyotropic lamellar phases with reticular distances as large as $8000 \AA$ We find that the rigidity constant $K$ of such systems compares to $k_{\mathrm{B}} T$ and we find evidence that the lamellae of highly oll swollen phases include curved defects
\end{abstract}

\section{Introduction.}

Lyotropic lamellar phases [1] are made of water (resp. o1l) lamellae stabilized by a surfactant bilayer and embedded in oil (resp water) Their striking and challenging property is that the repeat distance can reach $10000 \AA$ [2] and thus these phases exhibit Bragg light scattering. They also show an important birefringence indicatıng a long range orientational order. These systems appeal to a lot of interest and activity because they offer a unique opportunity to study the interactions between lamellae and may also constitute a very first model system for an « infinite » fluctuating membrane [3]. The interactions usually invoked in colloidal science (dispersion, electrostatic or hydration interactions) are not sufficient to explain the existence of these systems A clue to the comprehension of them was proposed by Helfrich [4] initially for swollen lecithın systems (bilayers of double-tailed surfactant separated by water). Helfrich pioneered a long range repulsive interaction due to the low rigidity and the self avoiding character of the membranes This interaction was experimentally underscored using different techniques quite recently [5-10].

Most of the properties of these phases are related to the elastic constants and particularly to

(*) URA 792 du CNRS

(**) URA 233 du CNRS 
the bending rigidity $K$ of the fluid membranes [11-16]. Different experiments have been performed on some lamellar phases and have shown that this rigidity constant is small, of order $k_{\mathrm{B}} T$

In this paper, we report results on the local state of the interfacial film obtained by electronic spin resonance (ESR) of labelled surfactants Two different systems have been studied .

- $\mathrm{CPCl}$ (cetylpyridınıum chloride)/brine/hexanol (bilayer of surfactant and cosurfactant molecules separated by brine) Salt is added to screen Coulombian repulsions

- OBS (octylbenzene sulfonate)/water/pentanol/decane (water swollen lamellae embedded in oil).

The structural properties of these systems have already received a lot of attention $[2,8,9$, 17] It has been shown by scattering techniques that the first system is stabilized by Helfrich's steric interaction and that the membranes were defect-free But the second system retains some of its mystery

- the smectic order becomes « harder» (2 or even 3 Bragg peaks in light scattering) for the extreme-swollen phases while there is no peak in the intermediate range [2],

- the lamellae composition as well as the apparent thickness change when going from the dilute to extremely dilute regime [2]

\section{Materials and method.}

$\mathrm{CPCl}$ is obtained from Fluka (purum grade) and further purified by two recrystallisations in water and one in wet acetone ( $2 \mathrm{~g}$ of water in $100 \mathrm{cc}$ acetone). Hexanol is also obtained from Fluka (puriss grade $>99 \%$, controlled by gas chromatography) and used with no further purification $\mathrm{NaCl}$ is obtained from Merck (pro analysis grade $>995 \%$ ) and water is doubly distılled OBS is synthesized and punfied as described elsewhere [18] 1-pentanol (Merck PA) and decane (Fluka purum) are used as received The samples are prepared by weighing and the compositions are given in table I.

Table I. - Composttion of the samples (in volume fraction)

\begin{tabular}{|c|c|c|c|c|c|}
\hline & Lamella & & & Diluent & \\
\hline System & Surfactant & Cosurfactant & Core & Solvent & Cosurfactant \\
\hline CPCl (A) & $\mathrm{CPCl}(462 \%)$ & $\begin{array}{c}\text { hexanol (53 } 8 \%) \\
-\end{array}$ & - & brine $02 \mathrm{M} \mathrm{NaCl}(996 \%)$ & hexanol (0 4\%) \\
\hline OBS (B) & OBS (32\%) & pentanol (23\%) & water (45\%) & decane (905\%) & pentanol (95\%) \\
\hline
\end{tabular}

The labelled surfactant $\mathrm{N}$-((2-dodecyl)-N-oxy-2-tetrahydrooxazolyl) propyl N-methyl morpholinıum methanesulfonate of formula :

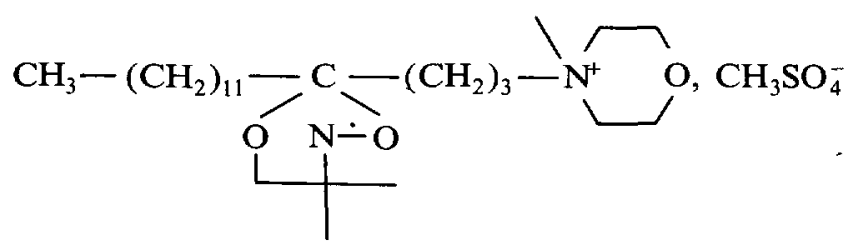

has been synthesized by Dvolàitzky [19]. This quaternary ammonium salt is highly amphiphilic and thus is strongly anchored within the interfacial film [19] The concentration of 
labelled surfactant molecules with respect to unlabelled surfactant molecules was between $10^{-3} \mathrm{~mol} / \mathrm{mol}$ to $6 \times 10^{-3} \mathrm{~mol} / \mathrm{mol}$ for the hyper-swollen phases (this concentration was higher in the more swollen phases to ensure a measurable signal) We have carefully checked that within this range (and even for a test sample between $5 \times 10^{-4}$ and $8 \times 10^{-3} \mathrm{~mol} / \mathrm{mol}$ ) the incorporation of labels inside the film did not induce any modification of the spectra, this rejects any possibility of label partitioning between the lamellae and the bulk (this will be addressed furthermore in the following of the paper)

All ESR experiments have been carried out on a E-9 Varian spectrometer at room temperature $\left(\simeq 20^{\circ} \mathrm{C}\right)$ Two kinds of cells have been used spherical cells (Spin et Techniques, Paris) with a 4-mm diameter in order to obtain an isotropic onentation and a " powder » spectrum (the lamellae coat the inside of the cell) and parallel-walls rectangular cells (200 $\mu \mathrm{m}$ path length) (Vitro Dynamics, Rockaway, New Jersey)

The orientation of the samples in rectangular cells is achieved by several heat treatments until getting a perfect homeotropic orientation as checked using a microscope with crossed polarizers

\section{Results and discussion.}

3.1 ORDER PARAMETER [20] - The very first information that we can obtain from the spectra is the order parameter $S$ of the labelled alkyl chain $\left(S=\frac{1}{2}\left\langle 3 \cos ^{2} \alpha-1\right\rangle\right.$ with $\alpha$ the angle between the normal to the labelled cycle and the normal to the lamellae) All the recorded spectra were characteristic of lamellar phases the order parameter is about 04 as in previous studies [21]. Since the labelled surfactant molecule is notably different from the unlabelled surfactant molecules ( $\mathrm{CPCl}$ or $\mathrm{OBS}$ ) that surround it (the side cycle constitutes a non negligible bulge), we cannot claim that the order parameter that we actually measure is the order parameter of the molecules of the interfacial film; nevertheless it does reflect the molecular packing of the interfacial film (the denser the film, the higher the parameter). The order parameter measurements of the water-swollen (referred as A in the following) and oilswollen (B) phases are reported in figure 1

The order parameter is higher in the water swollen sample A than in the oll-swollen B This

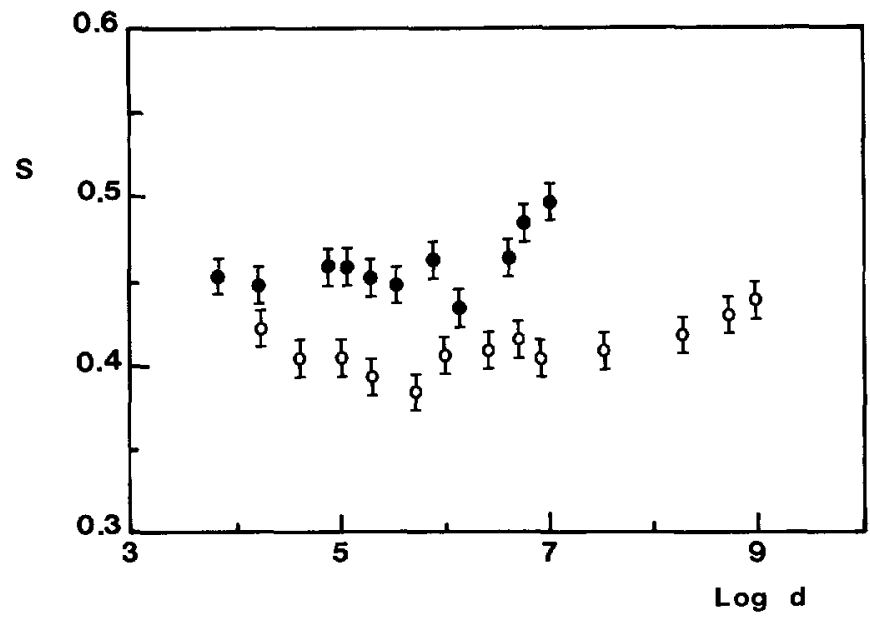

Fig 1 - Order parameter versus the logarthm of the retıcular distance $d(\bullet)$ sample A (CPCl), (O) sample B (OBS) 
indicates a higher compacity of the A film. The principal reason we can imagine for this is that an A lamella (of thickness $d_{0}=265 \AA$ ) is a true bilayer while B is water swollen $\left(d_{0}=35 \AA\right)$

The polarity of the samples can be deduced from the trace of the hyperfine tensor of the interaction of the electronic spin and the nitrogen nuclear spin; it remains constant throughout the whole dilution range for both systems : this proves that the anchoring quality of the labelled surfactant does not change upon swelling (and this is another proof of the nonoccurrence of partioning of the labelled molecules) :

\section{LAMELLA FLUCTUATIONS AND RIGIDITY CONSTANT MEASUREMENTS}

321 Method - A method for determining the rigidity constant of lamellar phases has been developed and is fully described in a recent conference proceeding book [22]. We will nevertheless expose it here once again. The basic principle is to compare the ESR spectra of samples contained in spherical cells inducing an isotropic orientation (" powder» spectra) with the ESR spectra obtained in rectangular cells which induce an homeotropic anchoring of the lamellae (" oriented » spectra, see materials and method) The spectroscopic data of the label embedded in the interfacial film (1.e. hyperfine splittings and line widths) have been obtained for each sample by simulation of the « powder » spectra using Lorentzian lineshapes and weighing each orientation of resonance by a $\sin \theta$ factor (isotropic).

We then determine the angular spread of disorientation of the lamellae in the rectangular cells due to fluctuations We arbitrarily assume that locally the interfacial film is a spherical cap (which is a deformation at minimal surface) and determine $\theta_{0}$ which is the half angle of the cone defined by the spherical cap (by integrating over $\theta$ until $\theta_{0}$ with a $\sin \theta$ ponderation), we compare these simulated spectra with the oriented spectra, obtained either in a parallel geometry (the normal of the cell walls parallel to the magnetic field) or in a perpendicular geometry (this maximum disorientation $\theta_{0}$ is of course equal to $\pi / 2$ for the isotropic case). We should stress at this point that $: 1$ ) this method is sensitive to very small undulations of the lamellae, 11) it is not sensitive to the sign of the curvature and 111) it is not very accurate for large disorientations

The characteristic time of the spin labelling technıque is equal to $10^{-8} \mathrm{~s}$ this means that molecular motions with characteristic times smaller than $10^{-8} \mathrm{~s}$ will not be observed (the average position is then recorded). Concerning lamellae, we can estimate from the dispersion of the undulation mode [6] that undulations with wavelengths smaller than $100 \AA$ are not observed (the lamellae are seen as flat at this scale) The recorded spectrum is then a superposition of spectra corresponding to all the orientations of the lamellae (of wavelengths larger than $100 \AA$ ) the maximum disorientation $\theta_{0}$ represents an average of the maximum disorientations over time and space. It is then difficult to determine exactly $\left\langle\theta^{2}\right\rangle=$ $\langle\theta(\mathbf{0}) \theta(\mathbf{r})\rangle$ from $\theta_{0}$ If we omit the time fluctuations of the lamellae, we found from a numerical integration that $\left\langle\theta^{2}\right\rangle \simeq 0.9 \theta_{0}^{2}$, including these fluctuations, we will write $\left\langle\theta^{2}\right\rangle=\alpha \theta_{0}^{2}$ with $\alpha$ a numerical factor of order unity (Note that our previous studies [5, 21, 22] would correspond to $\alpha=2$ in this frame)

322 Fluctuations theory - The curvature energy (per unit area) of the interfacial film reads $[11,23]$

$$
E=\frac{1}{2} K\left(\frac{1}{R}-\frac{1}{R_{0}}\right)^{2}
$$

where $K$ is the rigidity constant (with energy dimension), $R$ is the total radius of curvature and $R_{0}$ is the spontaneous radius of curvature which is the radius of curvature that the interface 
would adopt in absence of any interaction Dealing with lamellae, it is legitımous to assume that $R_{0}^{-1}=0$. To this energy, we add the steric repulsive term of Helfrich $U=a_{0} \frac{\left(k_{\mathrm{B}} T\right)^{2}}{K d^{2}}$ where $a_{0}$ is a constant.

Using these two ingredients and makıng a classical mode analysis, it can be easily shown [11] that the variation of the quadratic mean of the disorientation $\theta$ obeys [24]:

$$
\left\langle\theta^{2}\right\rangle=\frac{k T}{2 \pi K} \ln \left(\frac{\xi_{U}}{a}\right)
$$

$\xi_{U}$ is a correlation length governed by the competition between the flexibility of one lamella and the interactions with its neighbours

$\xi_{\mathrm{U}}=\left(\frac{K}{U^{\prime \prime}}\right)^{1 / 4}$ with $U^{\prime \prime}$ the second derivative of the interaction potential $U$ with respect to $d$, the repeat distance, $a$ is the minımum radius of curvature possible (we will take it equal to the half thickness of a lamella) Notice that $\xi_{U} \rightarrow \xi_{K}$ when $\left\langle\theta^{2}\right\rangle \rightarrow 1$, i e that the correlation length becomes equal to the persistence length introduced by de Gennes and Taupin [11] $\left(\xi_{\mathrm{K}}=a \exp \left(\frac{2 \pi K}{k T}\right)\right)$ when the lamella has lost the memory of its orientation. The computation of $U^{\prime \prime}$ yields the final formula :

$$
\left\langle\theta^{2}\right\rangle \simeq \frac{k T}{2 \pi K} \ln \left\{\left(6 a_{0}\right)^{-1 / 4}\left(\frac{K}{k T}\right)^{1 / 2} \frac{d}{a}\right\} .
$$

This formula will constitute our principal formula to determine the rigidity constant.

3.23 Rigidity constant estimation. - In figure 2, $\theta_{0}^{2}$ is plotted with respect to $\ln d$ for the water-swollen (A) and oll-swollen (B) samples up to $800 \AA$ For B samples, the "oriented » and «powder » spectra are identical for $d \geqslant 800 \AA$ We can imagine two reasons for that

1) We cannot obtain a perfect onentation in the rectangular cells. For the most swollen phases, the optical observation of the usual textural defects (like oily streaks) is quite difficult in $200 \mu \mathrm{m}$ cells, and this disabled us to get a perfect control of the onentation.

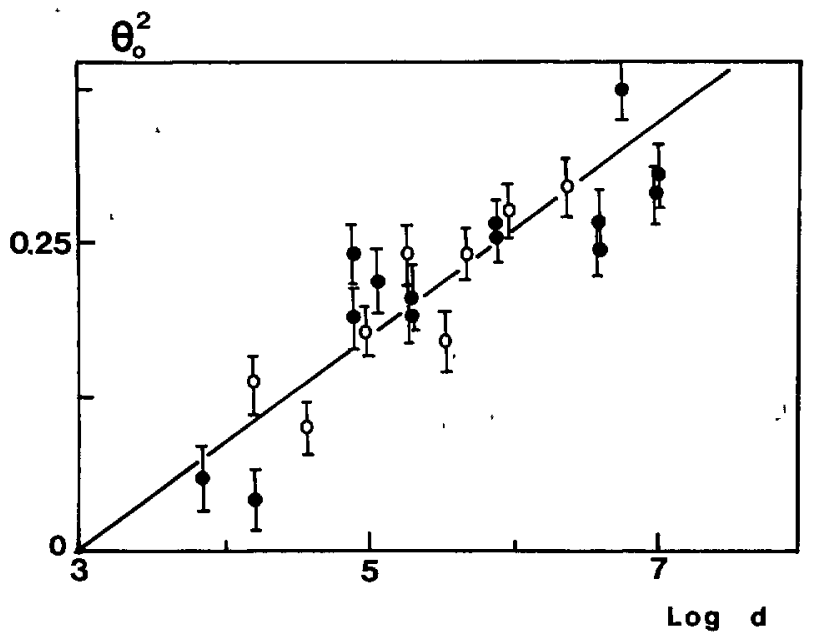

Fig 2 - Square of the disorientation angle $\theta_{0}$ versus the natural logarithm (Log) of the reticular distance $d(\bullet)$ sample A (CPCl), (O) sample B (OBS) 
11) The lamellae are so much undulated that there is no difference between oriented and powder spectra

From the slopes of figure 2, we deduce the same rigidity constant for both systems : $K \simeq 2 / \alpha k_{\mathrm{B}} T$

The rigidity constant can also be obtained from the intercept of the $\langle\theta\rangle^{2}=f(\ln d)$ plot with the abscissa axis ; we obtain $K \simeq 066 k_{\mathrm{B}} T$ if we take $a=15 \AA$, that is the half lamella thickness as determined by X-Ray scatterıng at small swelling ratio (we also take $a_{0}=\frac{3 \pi^{2}}{128}$ as in Helfrich's original paper [4]; but note that the value for $K$ is not very dependent on $a_{0}$ )

We can compare this value with the rigidities obtained on different systems with the same experimental procedure and equation (2) (the following values assume $\alpha=2$ ):

- $K \simeq 4 \times 10^{-14} \mathrm{erg}$ for water. lamellae embedded in cyclohexane and protected with sodium dodecyl sulfate (SDS) (a cosurfactant (1-pentanol) is added until the appearance of birefrungence) [5]

- $K \simeq 4 \times 10^{-14} \mathrm{erg}$ for bilayers of $\mathrm{C}_{12} \mathrm{E}_{5}$ embedded in water (repeat distance $50 \AA$, $\mathrm{C}_{12} \mathrm{E}_{5}$ is a nonionic surfactant where the hydrophobic chain is an aliphatic chain of 12 carbon atoms and the hydrophilic chain is made of 5 ethylene oxides) [25].

$-K \approx 3 \times 10^{-14}$ erg for bilayers of $\mathrm{C}_{12} \mathrm{E}_{6}$ embedded in water (repeat distance $50 \AA$ ) [25]

$-K \simeq 4 \times 10^{-14} \mathrm{erg}$ for water/Ukanil 36/heptane or $\left(\mathrm{CH}_{3}\right)_{3}-\mathrm{S} 1-\mathrm{O}-\mathrm{S} 1-\left(\mathrm{CH}_{3}\right)_{3}$ (repeat distance $65 \AA$, surfactant concentration $58 \%$ in water before oll addition, Ukanıl 36 is an industrial nomionic surfactant of cloud point $\left.36{ }^{\circ} \mathrm{C}\right)[26,27]$

$-K \approx 15 \times 10^{-14} \mathrm{erg}$ for water/Ukanil 36/silanol $[26,27]$ (of formula<smiles>C[Ge](C)(O)[SiH2]O</smiles>

It is not surprising to find that $K$ is about $k T$ for all these systems since they are in the vicinity of droplet microemulsions in phase diagrams If $K$ were much smaller than $k T$, only micellar systems could be obtained The smaller value for $K$ with the last system which incorporates silanol may reflect the molecular interaction of the interfacial film with the silanol (1 e the $\mathrm{OH}$ end-groups of the silanol can interact with the surfactant molecule [26, 27]).

As already mentionned in [27], it has been found for the OBS system that the lamella thickness $d_{0}$ as deduced from structure experiments (1 e X-rays or light scattering,

$$
d_{0}=d \Phi_{\mathrm{L}}
$$

$d$ is deduced from the Bragg peak and $\Phi_{\mathrm{L}}$ the lamella concentration from the sample composition) is increasing upon dilution of the membranes This could be explained from the large crumpling of the lamellae, the apparent thickness is related to the true thickness $d_{0}^{\prime}$ by :

$$
d_{0}=d_{0}^{\prime} \frac{S}{S^{\prime}}
$$

where $S$ is the true surface of the lamella and $S^{\prime}$ the projected surface $\left(S>S^{\prime}\right)$. Helfrich [12] 

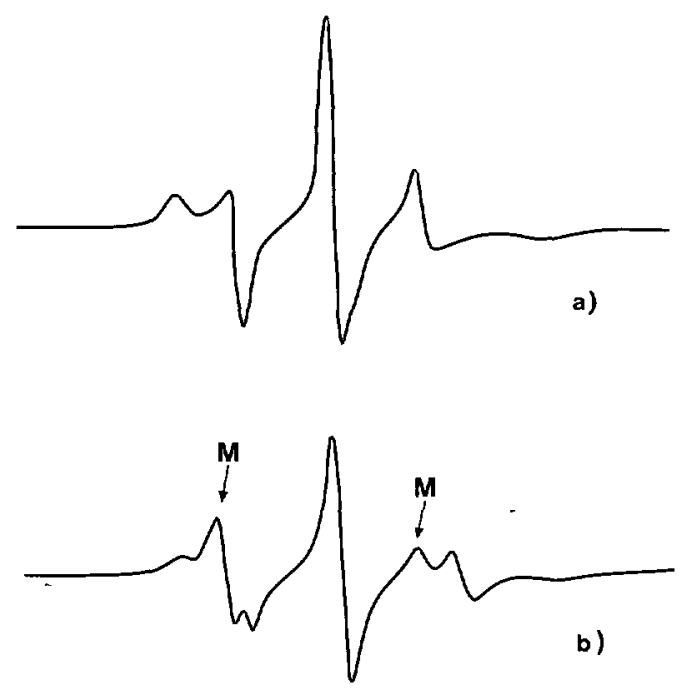

Fig 3 - «Powder » spectra of a) a $d=100 \AA$ sample (B), b) a $d=8300 \AA$ sample (B) showing the additional spectrum $M$ due to defects

has shown that $\frac{S^{\prime}}{S}=\langle\cos \theta\rangle$. This approach leads to the renormalization of the rigidity constant $[15,16]$.

3.3 Defects IN THE OIL HyPERSWOLlEN PHASE - As already observed in the first experiments performed on these kinds of systems [21], the ESR spectra of the most swollen $B$ phases are composite (while the spectra of A phases and concentrated B phases are "pure »): they are constituted of a "slow» spectrum ( $1 \mathrm{e}^{*}$ the correlation time stands in the slow tumbling regime [20]) characteristic of the lamellae plus a "fast " spectrum (the hyperfine splittıngs are totally averaged) (F1g. 3). Very curved domains have been shown to be responsible for this extra spectrum [21], they should be due to intrinsic defects such as pores for the system under study (the radius of curvature of the defects is half the lamella thickness $\simeq 18 \AA$ ) We have added to $1 \mathrm{cc}$ of a $d=6000 \AA$ sample $10 \mu \mathrm{l}$ of 1 -pentanol in order that the system enters the 1sotropic phase (which should be $\mathrm{L}_{2}$ swollen micelles) and we have actually checked that the extra spectrum has the same features as this isotropic spectrum We were thus able to simulate the composite spectra by adding a defect component with proportion $p$ according to

$$
y(H)=(1-p) \frac{y_{0}(H)}{p_{0}}+p \frac{y_{1}(H)}{p_{1}}
$$

$y(H)$ is the total microwave absorption, $y_{0}(H)$ the lamella component, $y_{1}(H)$ the defect component, $p_{\imath}=\int y_{l}(H) \mathrm{d} H$ where $H$ is the scanning magnetic field. The results are plotted in figure 4 The percentage of highly curved surface drastically increases for samples where the oriented and powder spectra are no more discernable. Let us notice that the Bragg peak reappears for the same dilutions. We do think that these defects are intrinsic to the phase because they do not anneal even after the repeated and severe heat treatments performed to orient the samples. We have also checked that the presence of defects is not due to the added 


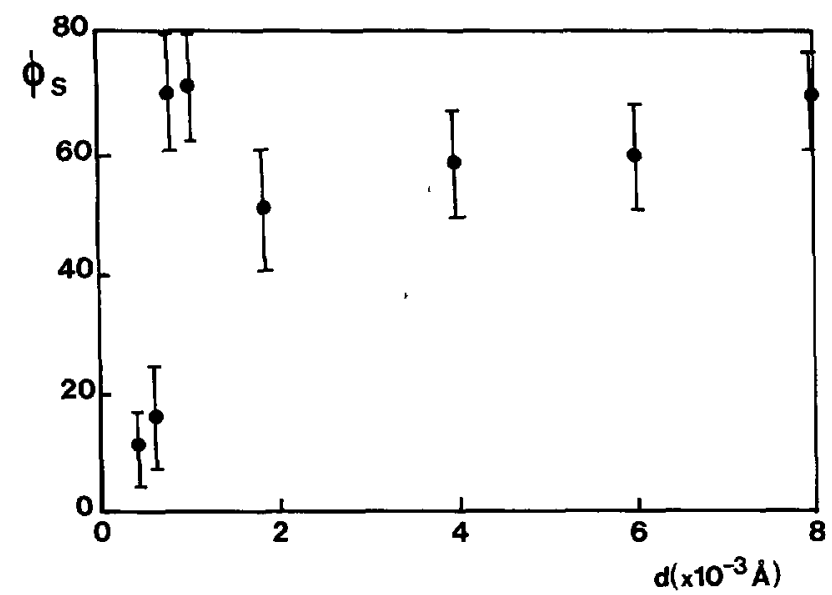

Fig 4 - Fraction of curved surface for sample (B) versus reticular distance (= fraction of labelled surfactant molecules in curved regions)

labelled surfactant. If we increase the number of labelled molecules inside the film, the proportion of curved area does not change

We 'should note that the presence of defects changes the thickness of the lamellae the actual thickness of the lamellae should be larger than the thickness given by equation (3) or (4), a rough estimation would give an increase of the thickness by a factor as large as 4 in the case of pores of radius $100 \AA$ for the most swollen samples. We have no satisfactory explanation for the presence of such a large proportion of curved area We have nevertheless already noted [28] that spin labelling may overestimate the number of defects or could be sensitive of very labile defects as « dynamic pores " which are not seen by other methods. It would be interesting to understand if these defects are necessary to the stability of these hyperswollen phases (which is not clearly explained from the entropic repulsive interaction)

\section{Conclusion.}

We have reported a spin labelling study of swollen lamellar phases Our original aim was to investigate the amplitude of orientational fluctuations of the lamellae when they are separated by thousands of Ångstroms. For these hyperswollen phases, we cannot distınguish between the "oriented" and "powder" spectra and we are unfortunately not able to attribute this experimental behaviour to a poor orientation of the samples or to giant orientational fluctuations We have thus falled with respect to our original goal Nevertheless we have estimated the rigidity constants of our systems and found a value close to the thermal energy $k_{\mathrm{B}} T$. Other estimations of the rigidity constant $K$ on the same systems using light scattering have been performed [10] and a comparison between the obtained values should be interesting since the probed scales are different But unfortunately, these techniques cannot give a direct and model-free measurement of the rigidity (they depend on the hydrodynamical model) Moreover, we confirm the absence of intrinsic defects in the CPCl system (A). On the other hand, we have shown that the very swollen only phases (B) have a lot of defects in their lamellae. We have not found any pertinent answer to the stronger smectic order for extremely high dilutions of this latter system as observed by scattering techniques 


\section{Acknowledgments.}

We would like to thank Drs. J. Appell, D Chatenay, J. Marignan and G. Porte for helpful discussions and encouragement. This study has received partial financial support from PIRSEM (CNRS, grant no AIP 2004) and is a collaboration of the GRECO Microemulsions.

\section{References}

[1] Eckwall P, in « Advances in Liquid Crystals », G H Brown Ed (Academıc Press, New York) 1 (1975) 1

[2] Appell J., Bassereau P, Marignan J and Porte G, Collotd Polymer Scl 267 (1989) 600

[3] Nelson D., in « Random fluctuations and pattern growth Theory and experiments », NATO ASI, H E Stanley and N Ostrowsky Eds (Kluwer Academic Publishers, Dordrecht, The Netherlands), 1989

[4] HelfRICH W, Z Naturforsch 33A (1978) 305

[5] Di Meglio J. M, Dvolaitzky M and Taupin C, $J$ Phys Chem 89 (1985) 871

[6] Di Meglio J. M, Dvolaitzky M, Léger L and Taupin C., Phys Rev Lett 54 (1985) 1686

[7] Safinya C R, Roux D, Smith G S., Sinha S K, Dimon P, Clark N A. and Belloce A M., Phys Rev Lett. 57 (1986) 2518

Roux D and Safinya C R, $J$ Phys France 49 (1988) 307.

[8] Bassereau P, Marignan J and Porte G, J Phys France 48 (1987) 673

[9] Porte G, Marignan J, Bassereau P and May R, Europhys Lett 7 (1988) 713

[10] Nallet F, Roux D and Prost J, Phys Rev Lett 62 (1989) 276

Nallet F, Roux D and Prost J, J. Phys France 50 (1989) 3147

[11] De Gennes P. G and Taupin C., $J$ Phys Chem 86 (1982) 2294

[12] Helfrich W, $J$ Phys France 46 (1985) 1263

[13] Peliti L and Leibler S, Phys Rev Lett 54 (1985) $1690^{\circ}$.

[14] Huse D and Leibler S., $J$ Phys France 49 (1988) 605

[15] LipowsKi R and LeIBLer S., Phys Rev Lett 56 (1986) 2541

[16] LeIbler S and Lipowski S, Phys Rev B 35 (1987) 7004

[17] Larché F C, Appell J, Porte G, Bassereau P and Marignan J., Phys. Rev Lett 56 (1986) 1700

[18] Larché F C, Marignan J , Dussossoy J L and Rouvière J , Colloid Surf Sct 94 (1983) 964 Marignan J., Delichère A and Larché F C, J. Phys Lett France 44 (1983) L-609

[19] Dvolaitzky M and Taupin C, Nouv $J$ Chimie 1 (1977) 355

[20] See «Spın Labelling Theory and Applications », L J Berlıner Ed (Academic Press, New York) 1976

[21] Di Meglio J. M, Dvolaitzky M, Ober R and Taupin C, J Phys Lett France 44 (1983) L229

[22] Di Meglio J M, Dvolaitzky M and Taupin C., in « Physics of Complex and Supermolecular Fluids ", S. A Safran and N A Clark Eds (Wiley Interscience, New York) 1987

[23] Helfrich W., $Z$ Naturforsch 28C (1973) 693

[24] We use equation (IV 8) of reference [11] We measure the quadratic mean of the desonentation over the sample and not its lımit for infinite distance this introduces the factor 2 in the denominator The results for the rigidities are identical to the results of our previous works $[5,22]$ if we set $\alpha=2$ More detalls will be found in P Bassereau thesis (1990)

[25] Di Meglio J. M, Thèse, Paris 1984

[26] Messier A, Thèse, Parıs 1986.

[27] Messier A, Schorsch G, Rouvière J and Ténèbre L, Progr Collotd Polymer Sci 79 (1989) 249

[28] Allain M and Di Meglio J M, Mol. Cryst Liq Cryst 124 (1985) 115. 